\title{
A Phase I/Ila Trial Using CD19-Targeted Third- Generation CAR T Cells for Lymphoma and Leukemia
}

\author{
Gunilla Enblad', Hannah Karlsson ${ }^{1}$, Gustav Gammelgård', Jessica Wenthe ${ }^{1}$, Tanja Lövgren', \\ Rose Marie Amini', Kristina I. Wikstrom², Magnus Essand', Barbara Savoldo ${ }^{3}$, \\ Helene Hallböök ${ }^{4}$, Martin Höglund ${ }^{4}$, Gianpietro Dotti ${ }^{3}$, Malcolm K. Brenner ${ }^{3}$, \\ Hans Hagberg', and Angelica Loskog'
}

\begin{abstract}
Purpose: The chimeric antigen receptor (CAR) T-cell therapy has been effective for patients with $\mathrm{CD} 19^{+}$B-cell malignancies. Most studies have investigated the second-generation CARs with either CD28 or 4-1BB costimulatory domains in the CAR receptor. Here, we describe the first clinical phase I/IIa trial using third-generation CAR $\mathrm{T}$ cells targeting CD19 to evaluate safety and efficacy.

Patients and Methods: Fifteen patients with B-cell lymphoma or leukemia were treated with CAR T cells. The patients with lymphoma received chemotherapy during CAR manufacture and 11 of 15 were given low-dose cyclophosphamide and fludarabine conditioning prior to CAR infusion. Peripheral blood was sampled before and at multiple time points after CAR infusion to evaluate the persistence of CAR T cells and for immune profiling, using quantitative PCR, flow cytometry, and a proteomic array.
\end{abstract}

\section{Introduction}

Treatment of patients with relapsed, or resistant B-cell malignancies using CD19-directed chimeric antigen receptor (CAR) T cells has shown extraordinary results in patients with acute leukemia and lymphoma $(1,2-5)$. CAR T cells are autologous $\mathrm{T}$ cells genetically engineered to express a tumor-targeting CAR receptor. The CAR molecule consists of an antigen-recognizing extracellular domain, commonly a single-chain antibody fragment (scFv), and an intracellular signaling domain (6). The latter merges signaling domains from the T-cell receptor (TcR) complex and the costimulatory proteins. For full activation, $\mathrm{T}$ cells need

'Department of Immunology, Genetics and Pathology, Uppsala University, Rudbeck Laboratory C11, Uppsala, Sweden. ${ }^{2}$ VECURA, Karolinska University Hospital Huddinge, Stockholm, Sweden. ${ }^{3}$ Center for Cell and Gene Therapy, Baylor College of Medicine, Houston, Texas. ${ }^{4}$ Department of Medical Sciences, Uppsala University, Uppsala, Sweden.

Note: Supplementary data for this article are available at Clinical Cancer Research Online (http://clincancerres.aacrjournals.org/).

Current address for B. Savoldo and G. Dotti: University of North Carolina, Chapel Hill, North Carolina.

Corresponding Author: Gunilla Enblad, Uppsala University, Uppsala 751 85, Sweden. Phone: 461-8-611-0000; Fax: 4618611 5528; E-mail: gunilla.enblad@igp.uu.se

doi: 10.1158/1078-0432.CCR-18-0426
Results: Treatment with third-generation CAR T cells was generally safe with 4 patients requiring hospitalization due to adverse reactions. Six of the 15 patients had initial complete responses [4/11 lymphoma and 2/4 acute lymphoblastic leukemia (ALL)], and 3 of the patients with lymphoma were in remission at 3 months. Two patients are still alive. Best predictor of response was a good immune status prior to CAR infusion with high IL12, DC-Lamp, Fas ligand, and TRAIL. Responding patients had low monocytic myeloid-derived suppressor cells (MDSCs; CD $14^{+} \mathrm{CD} 33^{+} \mathrm{HLA}^{-} \mathrm{DR}^{-}$) and low levels of IL6, IL8, NAP3, sPDL1, and SPDL2.

Conclusions: Third-generation CARs may be efficient in patients with advanced B-cell lymphoproliferative malignancy with only modest toxicity. Immune profiling pre- and posttreatment can be used to find response biomarkers. Clin Cancer Res; 24(24); 6185-94.

costimulation via proteins such as CD28, CD27, and 4-1BB. Until now, clinically used CART cells included a signaling domain from either the CD28 or 4-1BB molecules. However, CD28 and 4-1BB signal through different pathways and may have complementary functions; CD28 is an early stimulator, whereas $4-1 \mathrm{BB}$ is more important later in the activation and expansion phases (7). Indeed, the experimental studies have shown that $\mathrm{T}$ cells stimulated via both CD28 and 4-1BB have greater activation of intracellular signaling pathways, more potent antitumor activity, and longer in vivo persistence than $\mathrm{T}$ cells stimulated by either moiety alone (8).

The aim of this first-in-man phase I/IIa study was to evaluate the safety and effect of the third-generation, CD19-targeting CAR T cells in patients with B-cell lymphoma or leukemia receiving no, or low dose, conditioning with cyclophosphamide and fludarabine prior to the CAR T-cell infusion. Patients were evaluated for clinical response, overall survival, and biomarker analysis by immuno-oncology proteomics.

\section{Patients and Methods}

Clinical trial design

The clinical trial (EudraCT 2013-001393-19/NCT02132624) included adult patients ( $\geq 18$ years; ECOG $0-2)$ with relapsed, or refractory, CD19-positive lymphoma or leukemia with no other curative treatment options. All patients provided written informed consent and were treated at the Uppsala University 


\section{Translational Relevance}

The study shows how preclinical development of the thirdgeneration CART cells performed at Baylor College (Houston, TX) could be translated into a clinical study and clinical benefit could be provided to the patients in Sweden. When the study was initiated, it was one of the first studies of CAR T cells outside the United States. Furthermore, the study shows that the immune status of the patient is important for the response to CART cells and the finding might contribute to the design of future studies of CAR T cells and thus the future development of this promising therapy.

Hospital (Uppsala, Sweden). The trial was approved by the Medical Product Agency and by the regional Ethical Review Board and conducted in accordance with the declaration of Helsinki. The trial was a single-center phase I/IIa study. In phase I, patients were treated with increasing doses of CAR T cells ranging from $2 \times 10^{7}$ to $2 \times 10^{8}$ cells $/ \mathrm{m}^{2}$. In phase IIa, patients were treated with $2 \times 10^{8}$ cells $/ \mathrm{m}^{2}$, provided no serious toxicity occurred at lower dose levels. After inclusion, patient blood was procured for CAR T-cell manufacture. The CAR T-cell manufacturing procedure ranged from 2 to 4 weeks and thereafter safety and control measurements were completed during an additional 2 weeks. During manufacture, the patient was treated with chemotherapy to reduce the tumor burden and maintain the patient. A wide range of chemotherapy was allowed and the treatment was chosen accordingly to the previous therapy and tumor type. Patients who progressed during CART-cell manufacture were not excluded. Eleven patients also received conditioning with intravenous low-dose cyclophosphamide $\left(500 \mathrm{mg} / \mathrm{m}^{2}\right)$ on day 4 and fludarabine $\left(25 \mathrm{mg} / \mathrm{m}^{2}\right)$ from day 4 to day 2 (Table 1 ). On day 0 , CAR T cells were administered as an intravenous bolus dose. The patients were followed weekly with blood biochemistry, blood counts, and clinical visits. A first response evaluation was done with a bone marrow examination or a clinical assessment at week 5. After 3 months, the first effect evaluation was planned according to protocol $(9,10)$. However, CT or bone marrow investigation was performed earlier if clinically indicated. The patients were then followed at least every 3 months.

\section{Preparation of CAR T cells}

The CAR T cells were produced by the Vecura GMP facility at Karolinska Hospital (Huddinge, Sweden). Briefly, $30 \mathrm{~mL}$ peripheral heparinized blood was sampled and transported to Vecura at room temperature. The peripheral blood mononuclear cells (PBMC) were prepared by Ficoll (GE Healthcare) density centrifugation, and if necessary (leukocyte count $>30 \mathrm{E} 9$ ) CliniMACS (Miltenyi Biotec) was used to deplete for $\mathrm{CD} 19^{+}$cells. The resulting PBMCs were cultured for 2 to 3 days in a 1:1 mixture of RPMI and Eagle's Hank's Amino Acids (EHAA) culture media supplemented with $10 \%$ FCS and $2 \mathrm{mmol} / \mathrm{L}$ L-Glutamine, in culture plates or flasks coated with anti-CD3 $(1 \mu \mathrm{g} / \mathrm{mL}$, OKT3, Miltenyi Biotec) and anti-CD28 (1 $\mu \mathrm{g} / \mathrm{mL}$, Miltenyi Biotec $)$ and from day 2 with added IL2 (200 IU/mL, Miltenyi Biotec). The cells were transduced with the GMP grade retroviral vector (Moloney murine leukima virus, MMLV) encoding the CAR SFG $\alpha \mathrm{CD} 19.28 .4-1 \mathrm{BB}-\zeta$ consisting of an anti-CD19 scFv region linked via a $\mathrm{CH} 2-\mathrm{CH} 3$ long hinge domain to the transmembrane and intracellular domain of $\mathrm{CD} 28$, the intracellular domain of 4-1BB, and the intracellular domain of the $\mathrm{CD} 3-\zeta$ chain in the mentioned order (11). The transduction was performed on plates coated with Retronectin (TaKaRa/Clonetech) and the transduced cells were continuously cultured in IL2-containing medium until the target cell number was reached. The CAR T cells were frozen in therapeutic doses. After quality control, the product was released and transported on dry ice to Uppsala University Hospital. Manufacturing failure where CART cells did not expand was seen in one of the 18 patients.

\section{Flow cytometry of CAR T-cell batches and patient samples}

Aliquots from the manufactured CAR T-cell batches, or PBMCs from patient blood pre- and posttreatment, were analyzed by flow cytometry to determine the cell phenotype. Briefly, cells were thawed and stained with antibodies purchased from BioLegend. The cells were washed and fixed with 1\% paraformaldehyde in PBS prior analysis using FACSCanto II (BD Biosciences). The following antibodies were used as indicated in the figures: antihuman Ig $(\mathrm{H}+\mathrm{L})$ (e.g., CAR scFv detection; polyclonal), CD3 (UCHT1), CD4 (OKT4), CD8 (SK1), CD45RA (HI100), CCR7 (G043H7), PD1 (EH12.2H7), CD40L (24-31), CD27 (M-T271), CD127 (A019D5), FoxP3 (206D), CD14 (HCD14), CD33 (WM53), HLA-DR (L243), and CD11b (ICRF44), all with matching isotype antibody controls (MOPC-21, MPC-11).

\section{CAR detection in blood by qPCR}

Genomic DNA from PBMCs was prepared using the PureLink Genomic DNA Mini Kit and concentrations were determined using a NanoDrop 1000 (Thermo Fisher Scientific). Five-hundred nanograms of genomic DNA was analyzed by quantitative PCR using TaqMan Master Mix (Custom Plus TaqMan RNA Assay) with forward/reverse primers and probe specific for the thirdgeneration CAR. A standard curve of plasmid DNA containing the CAR construct was included for quantification. Reactions were run on a Bio-Rad CFX96, C1000 Thermal cycler (Bio-Rad Laboratories).

\section{Plasma proteomics}

Plasma samples, at baseline (pre) and post-CAR T-cell treatment ( 1 week, 5 weeks, and 3 months), were collected from heparin tubes prior to PBMC purification and stored at $-80^{\circ} \mathrm{C}$. The samples were analyzed using the Olink Immuno-Oncology array by Olink Proteomics AB. Relative values are expressed as linear NPX.

\section{Statistical analysis}

Statistics were calculated using Prism Software (Graphpad Software Inc.). Progression-free survival (PFS) was calculated from the date of CAR T-cell infusion to the date of clinical progression. Overall survival was calculated from the date of CAR T-cell infusion to death. Differences between survival curves were calculated using log-rank test, whereas correlations were calculated by Spearman rank correlation test. A $P$ value $<0.05$ was considered significant.

\section{Results}

Treatment using third-generation CAR T cells was safe

Nineteen patients were enrolled of whom 15 were treated with CAR T cells. Four subjects were not treated due to rapid progression leading to death prior to infusion $(n=2)$, death before peripheral blood was taken for CART-cell manufacturing $(n=1)$, 


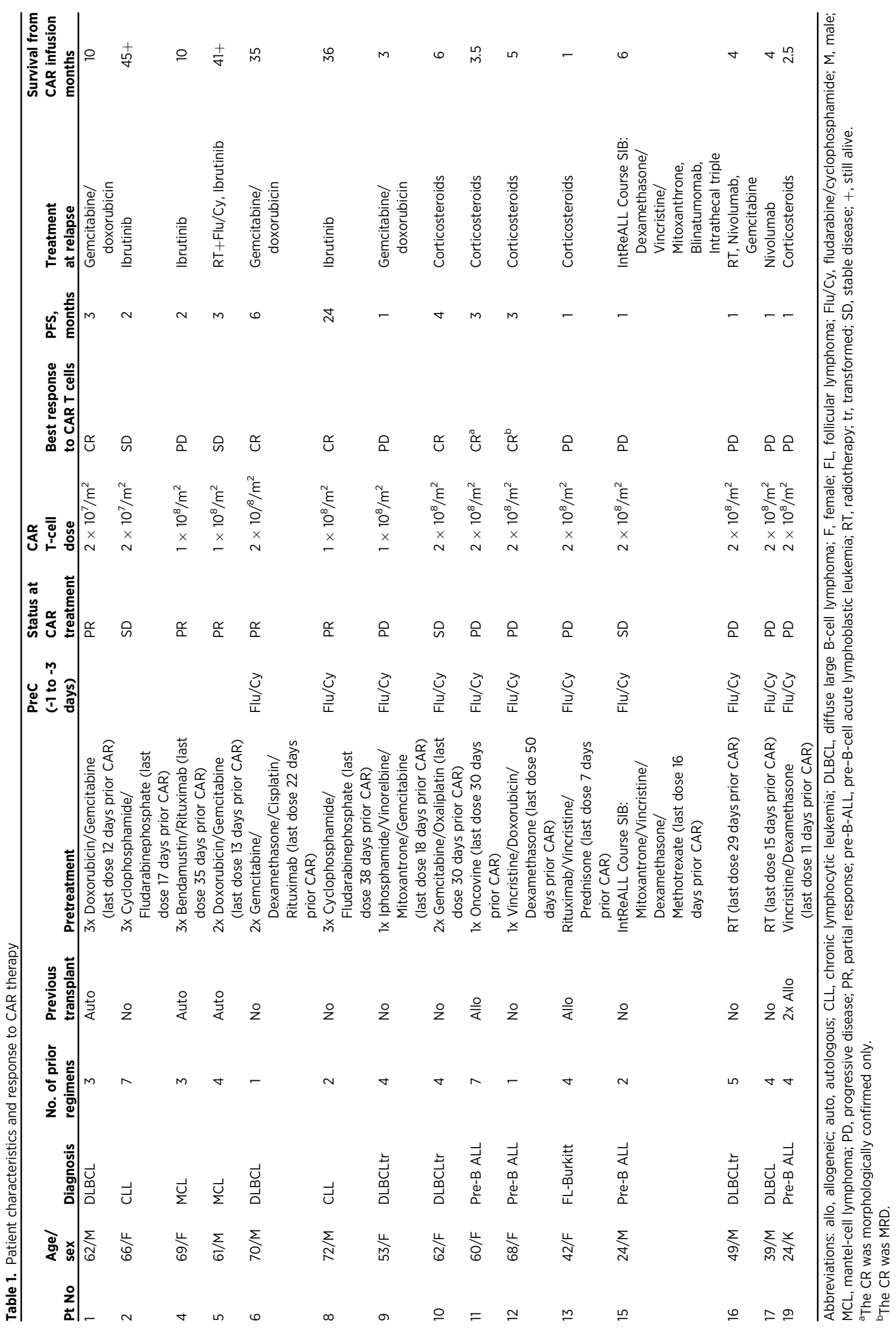


or to CAR manufacture failure $(n=1)$. The median age was 61 years (range 24-71 years). Eleven patients had B-cell lymphomas and four had B acute lymphoblastic leukemia (ALL; Table 1). There was no acute infusion-related toxicity during infusion of CAR T cells. A total of 154 related adverse events were recorded between grade 1 and 4 . During the first few weeks, most patients had mild symptoms of cytokine release, such as elevated Creactive protein (CRP) and/or IL6, chills, fever, fatigue, and flulike symptoms. However, 3 patients (nos. 1, 12, 13) developed a cytokine release syndrome (CRS), which required hospitalization. Patient no. 1 had fever and enlarged lymph nodes (without lymphoma) at day 35, which was considered a CRS grade 1 and it resolved spontaneously. At day 76, he was admitted to the ward due to fever, elevated CRP, and IL6. He also had hypotension and atrial fibrillation. He was treated with fluids and antibiotics but the condition did not resolve. A CT scan showed enlarged mediastinal nodes. Because of the suspicion of relapse, he was treated with corticosteroids and all symptoms resolved. Patient nos. 12 and 13 had fever and hypotension already the day after CART-cell infusion and developed CRS grade 2 and 3, respectively. In patient no. 13 , the condition required intensive care unit admission and the patient was given three doses of tocilizumab (dose $8 \mathrm{mg} / \mathrm{kg}$ ) to resolve the CRS.

Two patients (nos. 11 and 13) experienced central nervous system (CNS) toxicity that required hospitalization. Patient no. 11 had chemotherapy-resistant ALL with relapse after an allogeneic transplant. She was treated with $2 \times 10^{8}$ cells $/ \mathrm{m}^{2}$ after preconditioning with low-dose cyclophosphamide and fludarabine. She experienced no early adverse events except sore throat and increased IL6 and CRP. At day 20, she was admitted to the county hospital due to headache, aphasia, mild confusion, and difficulty in walking. MRI of the head showed no sign of encephalitis and her symptoms resolved within 10 days without intervention. Similarly, patient no. 13 experienced aphasia on day 20. She also had balance problems and dizziness and a subsequent seizure; MRI again showed no evidence for encephalitis. Her symptoms also resolved within 10 days. None of the patients in this trial had symptoms of cerebral edema. All adverse events are listed in Table 2.

Therapy response and survival of patients treated with thirdgeneration CAR T cells

In total, 6 of the 15 patients achieved an initial complete response (CR), 2 of 4 with ALL, and 4 of 11 with lymphoma (Fig. 1). The two CRs in ALL was in one case MRD (based on flow cytometry), and in one case MRD unknown. At 3 months, 3 lymphoma patients were still in CR (Table 1). The median response duration was 5 months (3-24). Both ALL patients relapsed at 3 months. In patient no. 11, the relapse was CD19 negative by flow cytometry. There was no relation between CAR T-cell dose and response. However, 2 of the 3 patients with severe CRS, and one of the 2 patients with CNS toxicity, had a CR. Four patients had good effect of subsequent treatment after relapse (nos. 1, 2, 5, and 6). The median survival for all patients was 6 months. The median survival for patients with lymphoma was 10 months, whereas it was 4 months for the patients with ALL (Fig. 2A). Patients who were responsive to chemotherapy during CAR T-cell manufacture had a better overall survival than the remaining patients (Fig. $2 \mathrm{~B}, P=0.0002$ ). Two of the lymphoma patients not responding to CAR T cells despite persisting CAR T cells in blood were given one dose of anti-PD1 antibody therapy (nivolumab), but this did not convert progression. Overall, 2 of the 15 patients are surviving long-term but with persistent disease (>27-36 months).

\section{CAR batch quality and CAR blood levels post infusion}

Producing CAR T cells from $30 \mathrm{~mL}$ of blood was consistently feasible for the planned CART-cell doses. The average fold change was around 60 (range: 10-180, see Supplementary Table S1). Most batches had $>50 \%$ CAR transgene expression and consisted of $\mathrm{T}$ cells with mixed phenotypes (Fig. 3A). Among the $\mathrm{CD}^{+}{ }^{+} \mathrm{CD} 4^{+}$CAR T cells, the effector memory population dominated. In contrast, the $\mathrm{CD}^{+} \mathrm{CD}^{+} \mathrm{CAR} T$ cells were dominated by an effector phenotype. Up to $15 \%$ of CART cells expressed PD1 and Tim 3 , which is a sign of exhaustion. Up to $20 \%$ of the CD ${ }^{+}$ $\mathrm{T}$ cells expressed costimulatory CD40L, whereas both $\mathrm{CD} 4^{+}$and $\mathrm{CD}^{+} \mathrm{T}$ cells expressed CD27. None of these batch quality measures correlated with overall survival (Supplementary Fig. S1). Next, the presence of CAR T cells in patients' blood was evaluated by quantitative PCR. The copy number of CAR in total DNA from PBMCs varied but most patients had the highest number at week 1 post CAR treatment (Fig. 3B). The number of CAR copies at week 5 or at 3 months did not correlate with the overall survival. Rather, there was an inverse correlation at week 1 (Supplementary Fig. S1). However, CAR copies were still detected in those patients that responded best to CAR treatment (nos. 5, 6, and 8).

\section{Increasing monocytic myeloid-derived suppressor cells after} CAR T-cell infusion correlated with poor survival

$\mathrm{T}$ regulatory cells (Treg) remained stable over time in most patients and the percentage of Treg cells at different time points did not correlate with survival (Fig. 4A and data not shown). Myeloid-derived suppressor cells (MDSC) were divided into monocytic $\left(\mathrm{CD} 14^{+} \mathrm{CD} 33^{+} \mathrm{HLA}^{-} \mathrm{DR}^{-} \mathrm{CD} 11 \mathrm{~b}^{+}\right.$cells; Fig. 4B) or granulocytic $\left(\mathrm{CD} 14^{-} \mathrm{CD} 33^{+} \mathrm{HLA}^{-} \mathrm{DR}^{-} \mathrm{CD} 11 \mathrm{~b}^{+}\right.$cells; Fig. 4C). Responding patients had low levels of monocytic MDSCs and the level prior to treatment, and at 3 months posttreatment, was inversely correlated with survival (Fig. 4D). An increase in the percentage of monocytic MDSCs ( $>15 \%$ of total CD11b) was an indication of treatment failure. Granulocytic MDSCs remained low in most patients and there was no discernible correlation with survival (data not shown).

An immune status connected to a Th1 type of immunity prior therapy correlates with survival

Patients whose preinfusion plasma contained a high level of myeloid activation markers, such as IL12 and DC-Lamp, or lymphocyte effector markers, such as TRAIL and Fas ligand, had the longest overall survival (Supplementary Fig. S2). In contrast, high levels of soluble PDL1 (sPDL1; $P=0.0023$ ) and PDL2 (sPDL2; $P=0.0002$ ) post-CAR infusion, correlated with poor survival, as did high levels of IL6 $(=0.03)$, IL8 $(P=0.03)$, and NAP3 $(P=0.004)$. The $P$ values refer to week 5 (Supplementary Fig. S2).

\section{Discussion}

We report the first results of treatment with third-generation CAR T cells targeting CD19 in relapsed and refractory B-cell lymphoma and leukemia. The manufacturing of CAR T cells was successful in 17 of 18 patients (94\%). Fifteen patients could be 
Table 2. Adverse events post CAR infusion

\begin{tabular}{|c|c|c|c|c|c|c|c|c|}
\hline \multirow[b]{2}{*}{ Adverse event } & \multicolumn{2}{|l|}{ Grade 1} & \multicolumn{2}{|l|}{ Grade 2} & \multicolumn{2}{|l|}{ Grade 3} & \multicolumn{2}{|l|}{ Grade 4} \\
\hline & No. of patients & $\%$ & No. of patients & $\%$ & No. of patients & $\%$ & No. of patients & $\%$ \\
\hline Abdominal pain & & & 2 & $13.3 \%$ & 1 & $6.7 \%$ & & \\
\hline Alanine aminotransferase increased & & & 1 & $6.7 \%$ & & & & \\
\hline Amnesia & 1 & $6.7 \%$ & & & & & & \\
\hline Anemia & & & 1 & $6.7 \%$ & & & & \\
\hline Aspartate aminotransferase increased & & & 2 & $13.3 \%$ & 1 & $6.7 \%$ & & \\
\hline Ataxia & & & & & 1 & $6.7 \%$ & & \\
\hline Atrial fibrillation & 1 & $6.7 \%$ & & & & & & \\
\hline Atrial septal defect & 1 & $6.7 \%$ & & & & & & \\
\hline Atrial tachycardia & & & 1 & $6.7 \%$ & & & & \\
\hline Back pain & & & & & 1 & $6.7 \%$ & & \\
\hline Balance disturbance & 1 & $6.7 \%$ & 1 & $6.7 \%$ & & & & \\
\hline Chills & 7 & $46.7 \%$ & 2 & $13.3 \%$ & & & & \\
\hline CNS disturbance & & & & & & & 1 & $6.7 \%$ \\
\hline Cognitive disturbance & & & & & 1 & $6.7 \%$ & & \\
\hline Common cold & 2 & $13.3 \%$ & & & & & & \\
\hline Confusion & & & 2 & $13.3 \%$ & & & & \\
\hline Cough & 3 & $20 \%$ & & & & & & \\
\hline CRS & 1 & $6.7 \%$ & 1 & $6.7 \%$ & 1 & $6.7 \%$ & & \\
\hline Diplopia & & & 1 & $6.7 \%$ & & & & \\
\hline Dizziness & 4 & $26.7 \%$ & & & & & & \\
\hline Dysarthria & 1 & $6.7 \%$ & & & 1 & $6.7 \%$ & & \\
\hline Dysphasia & 1 & $6.7 \%$ & & & 1 & $6.7 \%$ & & \\
\hline Dyspnea & & & 1 & $6.7 \%$ & & & & \\
\hline Elevated CRP & 5 & $33.3 \%$ & 2 & $13.3 \%$ & 3 & $20 \%$ & & \\
\hline Elevated IL6 & 1 & $6.7 \%$ & 2 & $13.3 \%$ & 2 & $13.3 \%$ & & \\
\hline Enlarged lymph nodes in mediastinum & & & 1 & $6.7 \%$ & & & & \\
\hline Esophageal reflux & 1 & $6.7 \%$ & & & & & & \\
\hline Fainting & 1 & $6.7 \%$ & 1 & $6.7 \%$ & 1 & $6.7 \%$ & & \\
\hline Fatigue & 1 & $6.7 \%$ & 1 & $6.7 \%$ & 1 & $6.7 \%$ & & \\
\hline Fever & 3 & $20 \%$ & 4 & $26.7 \%$ & 1 & $6.7 \%$ & & \\
\hline Flu-like symptoms & 3 & $20 \%$ & 2 & $13.3 \%$ & & & & \\
\hline Flushing & 8 & $53.3 \%$ & & & & & & \\
\hline Hallucinations & 2 & $13.3 \%$ & & & & & & \\
\hline Headache & 2 & $13.3 \%$ & 1 & $6.7 \%$ & 1 & $6.7 \%$ & & \\
\hline Hypertension & 1 & $6.7 \%$ & 1 & $6.7 \%$ & 1 & $6.7 \%$ & & \\
\hline Hypoalbuminemia & 1 & $6.7 \%$ & 1 & $6.7 \%$ & & & & \\
\hline Hypokalemia & & & & & & & 1 & $6.7 \%$ \\
\hline Hyponatremia & 1 & $6.7 \%$ & & & 1 & $6.7 \%$ & & \\
\hline Hypotension & 2 & $13.3 \%$ & 1 & $6.7 \%$ & 1 & $6.7 \%$ & & \\
\hline Hypoxia & 1 & $6.7 \%$ & & & & & & \\
\hline Increased pain in whole body & & & & & 1 & $6.7 \%$ & & \\
\hline INR increased & 1 & $6.7 \%$ & & & & & & \\
\hline LDH increased & 1 & $6.7 \%$ & & & & & & \\
\hline Loss of appetite & 1 & $6.7 \%$ & & & & & & \\
\hline Low creatinine & 1 & $6.7 \%$ & & & & & & \\
\hline Myalgia & 1 & $6.7 \%$ & & & & & & \\
\hline Nausea & 4 & $26.7 \%$ & & & & & & \\
\hline Neck pain & & & 1 & $6.7 \%$ & & & & \\
\hline Non-cardiac chest pain & 1 & $6.7 \%$ & 2 & $13.3 \%$ & & & & \\
\hline Pain in enlarged lymph nodes, right submandibular & 1 & $6.7 \%$ & & & & & & \\
\hline Pain in head & & & 1 & $6.7 \%$ & & & & \\
\hline Pain in legs & & & 1 & $6.7 \%$ & & & & \\
\hline Pancytopenia & & & & & 1 & $6.7 \%$ & & \\
\hline Petechiae & 1 & $6.7 \%$ & & & & & & \\
\hline Platelet count decreased & & & & & 1 & $6.7 \%$ & & \\
\hline Ruddiness & 1 & $6.7 \%$ & & & & & & \\
\hline Seizure & & & 1 & $6.7 \%$ & & & & \\
\hline Sensory loss, left thigh & 1 & $6.7 \%$ & & & & & & \\
\hline Sensory loss, right cheek & 1 & $6.7 \%$ & & & & & & \\
\hline Skeletal pain & & & & & 2 & $13.3 \%$ & & \\
\hline Sore throat & 7 & $46.7 \%$ & & & & & & \\
\hline Suspected infection & 1 & $6.7 \%$ & & & & & & \\
\hline Swollen fingers & 1 & $6.7 \%$ & & & & & & \\
\hline Syncope & 1 & $6.7 \%$ & & & & & & \\
\hline Tachycardia & 4 & $26.7 \%$ & 1 & $6.7 \%$ & & & & \\
\hline
\end{tabular}

(Continued on the following page) 
Table 2. (Cont'd)

\begin{tabular}{|c|c|c|c|c|c|c|c|}
\hline \multirow[b]{2}{*}{ Adverse event } & \multicolumn{2}{|l|}{ Grade 1} & \multicolumn{2}{|l|}{ Grade 2} & \multicolumn{2}{|l|}{ Grade 3} & Grade 4 \\
\hline & No. of patients & $\%$ & No. of patients & $\%$ & No. of patients & $\%$ & No. of patients \\
\hline Thrombocytosis & 1 & $6.7 \%$ & & & & & \\
\hline Urinary retention & 1 & $6.7 \%$ & & & & & \\
\hline Weakness in legs & - & & 1 & $6.7 \%$ & 1 & $6.7 \%$ & \\
\hline Vertigo & - & & & & 1 & $6.7 \%$ & \\
\hline Vomiting & 1 & $6.7 \%$ & - & - & - & - & - \\
\hline
\end{tabular}

safely treated and the toxicity was relatively mild. The remission rates were similar as seen in studies with second-generation CAR $\mathrm{T}$ cells.

Third-generation CARs containing both CD28 and 4-1BB have shown superior in vivo expansion and antitumor efficacy in animal models compared with second-generation CARs (12). We have previously reported that both second- and third-generation CARs induce a similar phosphorylation pattern of intracellular signaling pathways. However, third-generation CARs have greater and prolonged activation status post antigen recognition (11). Besides the expected phosphorylation of molecules downstream of the $\mathrm{TcR}$, we also noted phosphorylation of proteins involved in regulation of the cell cycle, cell adhesion, and exocytosis. We hypothesized that third-generation CAR T cells could treat aggressive CD19-positive malignancies without the intensive conditioning used in most studies when this study was designed.

Overall, the treatment was safe with no fatal toxicity, which has been seen in other studies $(3,13)$. Most patients experienced mild CRS-like symptoms, such as sore throat, but only three were considered severe and required hospitalization, one of whom needed repeated tocilizumab treatment for symptom relief. The reasons for the apparently low toxicity profile in our study might be due to chance alone, to a low-dose conditioning regimen, or to a highly immunosuppressive milieu in patients with refractory disease. Two of the patients had severe CNS symptoms but they resolved spontaneously and there were no signs of brain edema by MRI. Recently, five deaths due to brain edema were reported after treatment with second-generation CD19-targeting CAR T cells by Juno Therapeutics (14), but the reason for this severe reaction is not currently understood and this outcome has also occurred at a low frequency in other CAR trials targeting CD19 $(15,16)$.

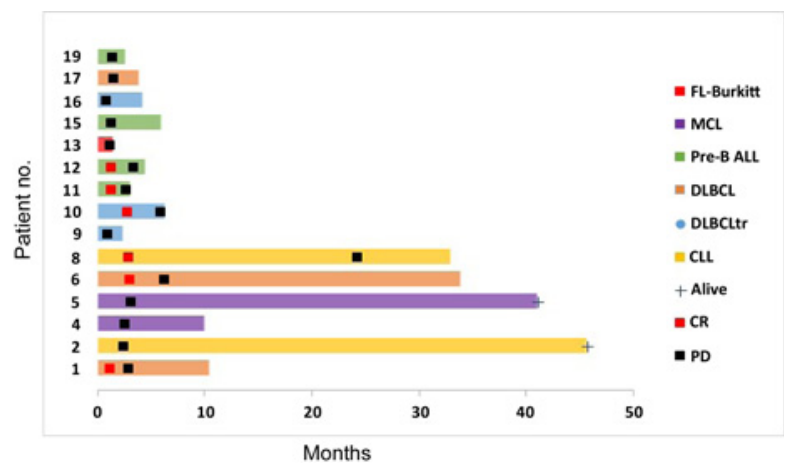

Figure 1.

Clinical course for all patients. DLBCLtr, diffuse large B cell lymphoma transformed from follicular lymphoma; FL-Burkitt, follicular lymphoma transformed to Burkitt lymphoma; MCL, mantle cell lymphoma; pre-B ALL, pre-B acute lymphoblastic leukemia; $C L L$, chronic lymphocytic leukemia; $C R$, complete remission; PR, partial remission; and PD, progressive disease.
Third-generation CARs have been used previously in patients. One study used CAR T cells targeting CD20 (17) and another study had HER-2-targeting CARs (18). Although CD20-targeted CARs were safe in the 4 treated patients, the first patient treated with HER-2-targeted CARs unfortunately experienced severe, lethal off-target toxicity. In the first study, the CAR was transiently expressed in the T cells, which would have self-limited persistent toxicity if third-generation CARs showed too potent. However, in the HER-2 study, a large number of cells $\left(1 \times 10^{10}\right)$ were infused with IL2, and the patient experienced near immediate severe distress, went into coma, and later died. Autopsy showed that CAR T cells were accumulated in the lung and the HER-2 antigen was expressed in the lung epithelium. Hence, off-target toxicity was considered the cause of death. Our trial did not show any elevated frequency or severity of adverse events compared with trials using second-generation CARs $(2,3,13,19)$.

The overall complete response rate in our study was 6 of the 15 treated patients. The response rate of the lymphoma patients was 4 of 11 . Two of the 4 ALL patients had initial CRs but all 4 patients

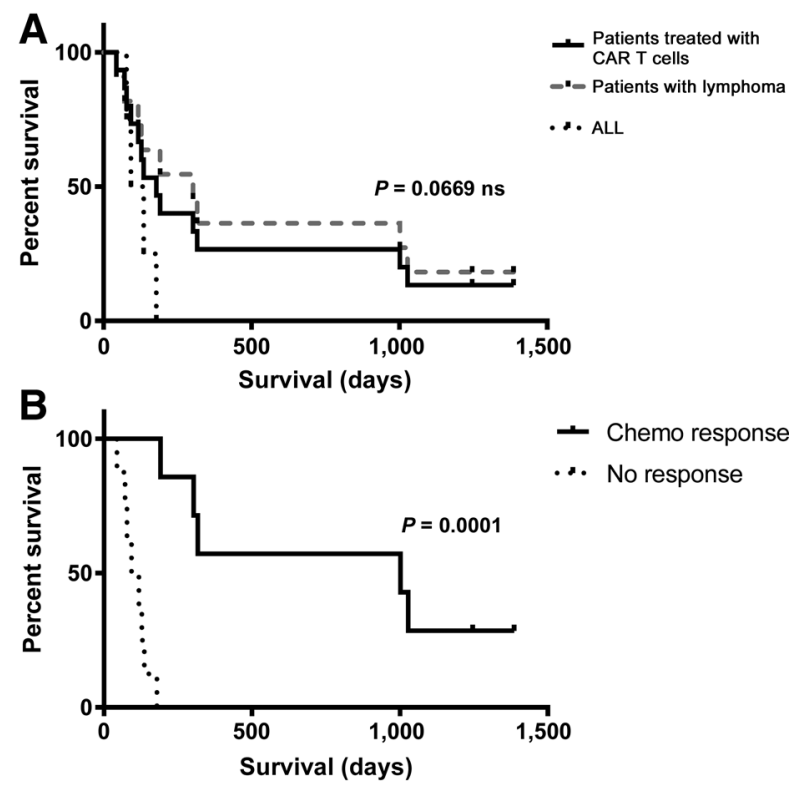

Figure 2.

A, Overall survival of patients treated with CAR T cells (black line; $n=15$ ). Patients with; lymphoma (gray broken line; $n=11$ ); acute lymphoblastic leukemia (ALL; black dotted line; $n=4$ ). The survival of lymphoma and ALL patients were not significantly different as evaluated by log-rank test. B, The patients were divided into those that did or did not respond to chemotherapy given during CAR T-cell manufacture (chemo response, black line; $n=7$, and no response, dotted line; $n=8$ ). The groups were significantly different as determined by log-rank test. 

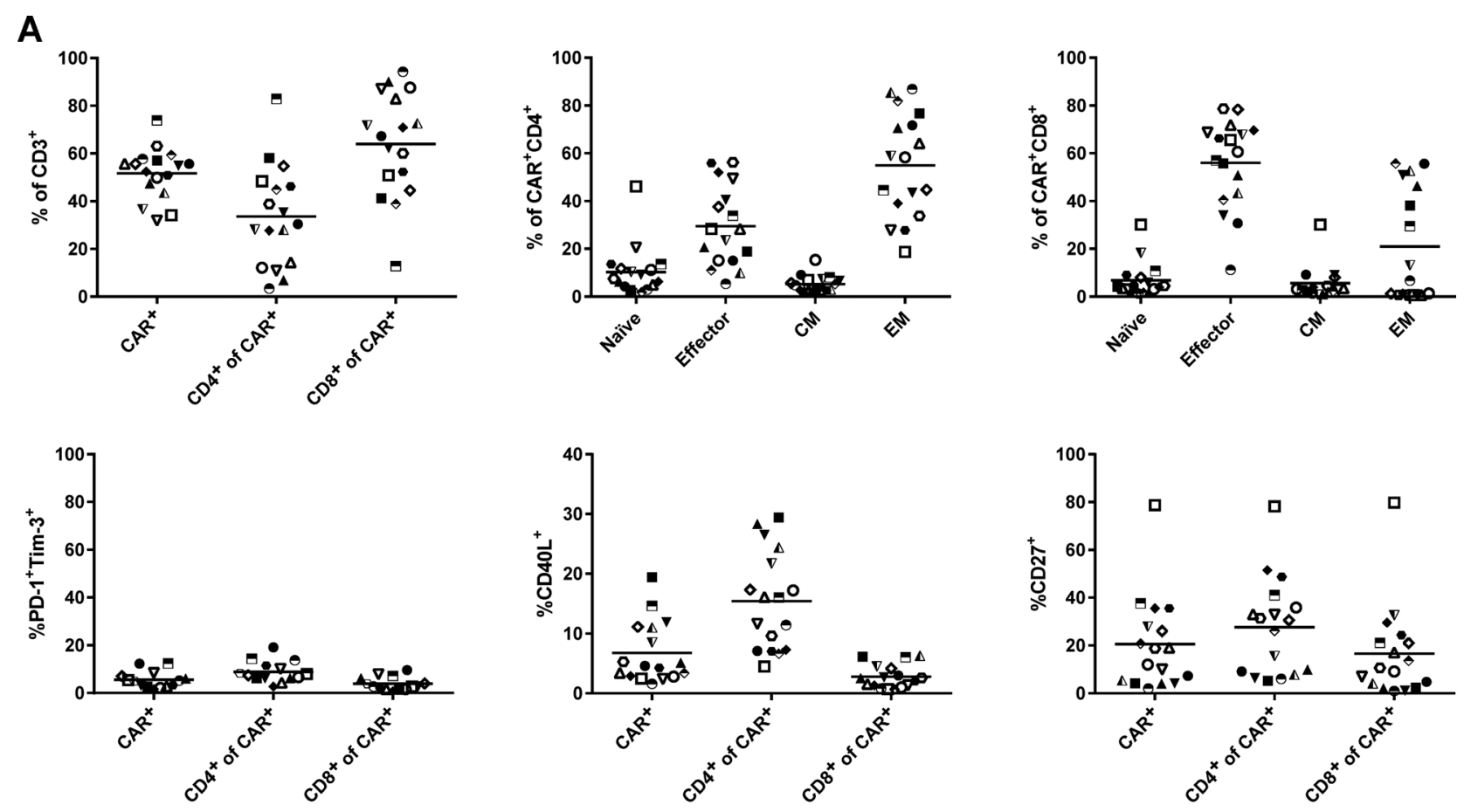

B

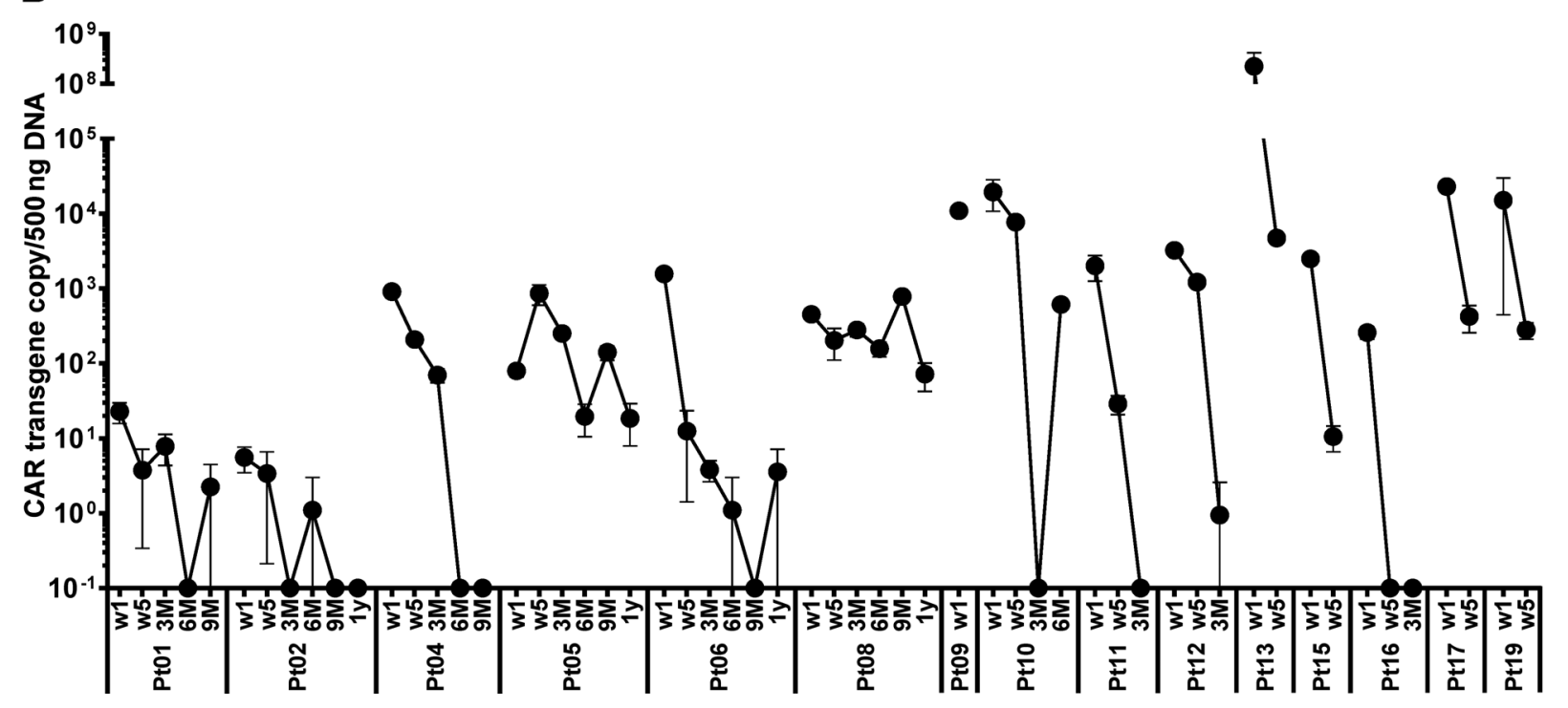

Figure 3.

The manufactured CAR T-cell batches were evaluated for phenotype using flow cytometry (A). CD45RA ${ }^{+} C \mathrm{CR} 7^{+} \mathrm{CD} 3^{+}$were considered a naïve T-cell population, whereas $C D 45 R A^{+} C C R 7^{-} \mathrm{CD}^{+}, \mathrm{CD}_{4} 5 \mathrm{RA}^{-} \mathrm{CCR} 7^{+} \mathrm{CD}^{+}$and $\mathrm{CD} 45 \mathrm{RA}{ }^{-} \mathrm{CCR7}{ }^{-} \mathrm{CD} 3^{+}$were considered effector, central memory $(\mathrm{CM})$, and effector memory (EM) T cells, respectively. B, The CAR gene copy number was evaluated in $500 \mathrm{ng}$ total DNA from peripheral blood mononuclear cells using quantitative PCR at different time points post CAR infusion ( $W=$ week; $M=$ month).

progressed, one with CD19-negative cells, and succumbed to disease. In the light of recently published phase II studies, the results of this study might seem inferior $(5,20)$. There are, however, differences in the inclusion criteria, conditioning regimes, manufacturing success, manufacturing time, preconditioning, and CAR T-cell product, which make it difficult to compare studies of CAR T-cell therapy. In our study, bridging chemotherapy was allowed and there was no restriction in including patients in the immediate need of treatment. The high rate of manufacturing success in our study led to a low proportion of excluded patients and a vigorous treatment to maintain the patient during manufacturing resulted in a high proportion of very sick patients. Indeed, we could show that the selection of patients also influenced the outcome as we could demonstrate 
A

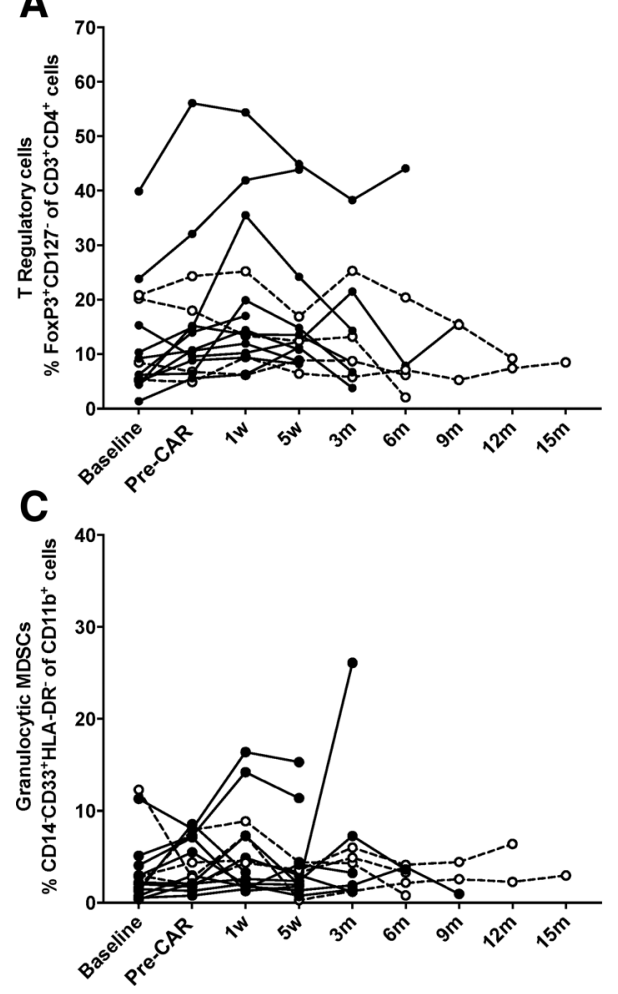

B

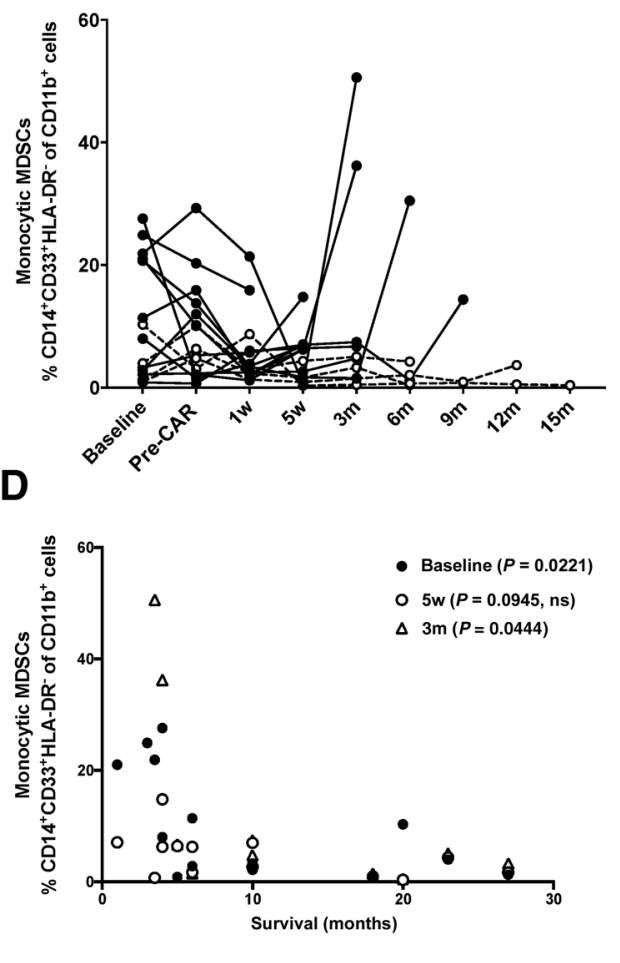

Figure 4.

Patients' peripheral blood mononuclear cells were analyzed by flow cytometry for the presence of immunosuppressive cells such as $T$ regulatory cells $(\mathbf{A}$; $\mathrm{CD}^{+} \mathrm{CD}^{+} \mathrm{CD} 127-\mathrm{FoxP3}^{+}$), monocytic MDSCs (B: $\mathrm{CD}_{14}{ }^{+} \mathrm{CD}_{3}{ }^{+} \mathrm{HLA}-\mathrm{DR}-$ of $\mathrm{CD}_{11 \mathrm{~b}^{+}}$) and granulocytic MDSCs (C; CD14$\mathrm{CD}_{3}{ }^{+} \mathrm{HLA}-\mathrm{DR}$ - of $\mathrm{CD}_{11 \mathrm{~b}^{+}}$). Monocytic MDSCs correlation with survival is shown in $\mathbf{D}$. The samples were analyzed at enrollment (baseline), after conditioning (e.g., day of CAR infusion), and at several time points post treatment ( $w$, week; $m$, month). Patients still alive are shown as broken lines (no. 2, 5, 6, and 8). Statistical significance was calculated using Spearman correlation test for nonparametric samples. that patients with a good immune status, and still responsive to chemotherapy, had a better outcome.

We hypothesized that third-generation CAR T cells could show increased persistence as compared with the second-generation CAR T cells (8) and indeed, CAR T cells were detectable up to 12 months posttherapy. However, there was no evident difference between persistence in our studies and published second-generation studies (e.g., ZUMA-1; ref. 5)

Turtle and colleagues treated 32 patients with CD19 ${ }^{+}$B-cell lymphoma using second-generation CAR T cells (13). The first 12 patients received cyclophosphamide with or without etoposide, and the subsequent 20 patients were conditioned intensely with combination of high dose of cyclophosphamide and fludarabine. Among the first 12, only one patient had a CR, whereas 9 of 20 had CR after intense conditioning. Hence, using third-generation CARs with low-dose conditioning, we achieved a similar response rate. However, Neelapu and colleagues recently showed that patients with diffuse large B-cell lymphoma (DLBCL) could be successfully treated by second-generation (CD28-based) CAR Tcells combined with low-dose conditioning and with a complete remission rate of $54 \%(5)$. The results gained by our protocol indicates that combining CD28 and 4-1BB in the CAR signaling domain may not provide improved in vivo activity, but these cells are certainly active and capable of inducing remarkable responses in patients. Both CD28 and 4-1BB signaling induce phosphorylation of the same target molecules (11) and the simultaneous signaling may not transform into a higher in vivo capacity in patients.

The CAR T cells were detected in patient blood for several months, for example, until the patients succumbed of disease. Nevertheless, the level of CAR transcripts at a given time point did not correlate with a longer survival, neither did we note a dose response. Unexpectedly, a high CAR copy number one week after CAR infusion predicted poor survival, but it may merely reflect the health status prior treatment in the patients in the final cohort.

We analyzed the patient plasma, immune cell phenotype, and batch quality to correlate markers with overall survival. Because of the small cohort size, the results are of guidance only and need to be confirmed in larger cohorts. Nevertheless, the best predictor of a response was a good immune status prior CAR infusion connected to a Th1 type of immunity characterized by high levels of IL12, DC-lamp, and a low proportion of monocyte-like MDSCs among myeloid cells. Furthermore, high levels of Fas ligand and TRAIL prior treatment correlated to a better survival. The activation status of both the myeloid and lymphoid linage may indicate a less-pronounced immunosuppression, which should be beneficial for CART cells upon infusion. In line with this, a predictor of poor response in our trial was a high level of monocytic MDSCs prior to therapy ( $>15 \%$ of total $\mathrm{CD} 11 \mathrm{~b}^{+}$cells), or rapidly increasing percentage of these cells postinfusion. Moreover, IL6, IL8, NAP3, PDL1, and PDL2 showed an inverse correlation with survival. Most of these molecules have been associated with immunosuppression in patients with cancer, although IL6 has a dual role (21-23), stimulating lymphocyte proliferation and activation but also inducing STAT-3 signaling, which is crucial for maintaining suppressive myeloid cells (24). Rapid increase of IL6 helps drive CRS during CAR therapy and because CRS symptoms commonly precede benefit, it is unclear whether high IL6 levels are beneficial or harmful for outcome. Nevertheless, in our study, high level of IL6 posttreatment correlated with poor survival in line with other published data describing the role of IL6 in lymphoma (25). 
The future development of CAR T-cell therapy might rest on combination therapies. One obvious choice would be to combine CAR T cells with PD-1 blockade. One patient with DLBCL has been reported to respond to PD-1 blockade (pembrolizumab) at progress on CAR T cells (26). In our study, 2 patients with DLBCL were treated with one dose of nivolumab but without apparent benefit. High levels of MDSCs were associated with poor outcome in our study and have been shown to correlate with poor prognosis in many cancer indications $(27,28)$. Myeloid cells can be reduced by gemcitabine without harming the lymphocyte population in patients with pancreatic cancer (29). Hence, gemcitabine treatment pre- and post-CAR infusion to control myeloid suppressor cells may be a means of enhancing long-term responses. In ALL, CAR T-cell treatment has often been complimented with an allogeneic transplant (30). It is appealing to use CART cells as a bridge to allogeneic transplant in selected patients. One advantage of this approach is that the CAR T cells are cleared with the allogeneic transplant, effectively obviating the B-cell aplasia seen in the long-term survivors.

Taken together, third-generation CD19-targeting CAR T cells that express both CD28 and 4-1BB costimulatory domains could safely be used in 15 patients with B-cell malignancy with $40 \%$ complete responses and 2 patients still alive. The cells could be administrated without conditioning, or after a low-dose cyclophosphamide/fludarabine. Our complete response rates are in the lower range but still comparable with those in studies using second-generation CARs. Three of the patients had serious adverse events (CRS, CNS, or combined) that required transient hospitalization. The best predictor of response was a good immune status prior CAR infusion with few monocytic MDSCs and higher levels of myeloid activation markers.

\section{Disclosure of Potential Conflicts of Interest}

G. Enblad is a consultant/advisory board member for Kite/Gilead. H. Karlsson is an employee of Olink Proteomics. B. Savoldo reports receiving commercial research grants from Cell Medica and Bellicum Pharmaceutical. G. Dotti reports receiving commercial research grants from Cell Medica and

\section{References}

1. Davila ML, Bouhassira DC, Park JH, Curran KJ, Smith EL, Pegram HJ, et al Chimeric antigen receptors for the adoptive T cell therapy of hematologic malignancies. Int J Hematol 2014;99:361-71.

2. Maude SL, Teachey DT, Porter DL, Grupp SA. CD19-targeted chimeric antigen receptor T-cell therapy for acute lymphoblastic leukemia. Blood 2015;125:4017-23.

3. Kochenderfer JN, Dudley ME, Kassim SH, Somerville RP, Carpenter RO, Stetler-Stevenson $\mathrm{M}$, et al. Chemotherapy-refractory diffuse large B-cell lymphoma and indolent B-cell malignancies can be effectively treated with autologous $\mathrm{T}$ cells expressing an anti-CD19 chimeric antigen receptor. J Clin Oncol 2015;33:540-9.

4. Schuster SJ, Svoboda J, Chong EA, Nasta SD, Mato AR, Anak Ö, et al Chimeric antigen receptor $\mathrm{T}$ cells in refractory B-cell lymphomas. N Engl J Med 2017;377:2545-54.

5. Neelapu SS, Locke FL, Bartlett NL, Lekakis LJ, Miklos DB, Jacobson CA, et al. Axicabtagene ciloleucel CAR T-cell therapy in refractory large B-cell lymphoma. N Engl J Med 2017;377:2531-44.

6. Essand M, Loskog AS. Genetically engineered T cells for the treatment of cancer. J Intern Med 2013;273:166-81.

7. Kawalekar OU, O'Connor RS, Fraietta JA, Guo L, McGettigan SE, Posey AD $\mathrm{Jr}$, et al. Distinct signaling of coreceptors regulates specific metabolism pathways and impacts memory development in CAR T cells. Immunity 2016;44:380-90.

8. Wang J, Jensen M, Lin $Y$, Sui $X$, Chen E, Lindgren CG, et al. Optimizing adoptive polyclonal $\mathrm{T}$ cell immunotherapy of lymphomas, using a
Bellicum Pharmaceutical, and is a consultant/advisory board member for MoldMed S.P.A. M.K. Brenner holds ownership interest (including patents) in Tessa Therapeutics and MarkerTherapeutics, and is a consultant/advisory board member for Unum Therapeutics, Torque Therapeutics, and Bluebird Bio. A Loskog is an employee of Lokon Pharma and a consultant/advisory board member for Nexttobe $\mathrm{AB}$ and Olink Proteomics. No potential conflicts of interest were disclosed by the other authors.

\section{Authors' Contributions}

Conception and design: G. Enblad, M. Essand, B. Savoldo, M. Höglund, G. Dotti, M.K. Brenner, H. Hagberg, A. Loskog

Development of methodology: B. Savoldo, G. Dotti, H. Hagberg

Acquisition of data (provided animals, acquired and managed patients, provided facilities, etc.): G. Enblad, G. Gammelgard, J. Wenthe, T. Lovgren, R. Amini, K.I. Wikstrom, H.Hallbook, M. Höglund, H. Hagberg

Analysis and interpretation of data (e.g., statistical analysis, biostatistics, computational analysis): G. Enblad, H. Karlsson, G. Gammelgard, J. Wenthe T. Lovgren, H. Hagberg, A. Loskog

Writing, review, and/or revision of the manuscript: G. Enblad, H. Karlsson, G. Gammelgard, J. Wenthe, T. Lovgren, R. Amini, B. Savoldo, H. Hallbook M. Höglund, G. Dotti, M.K. Brenner, H. Hagberg, A. Loskog Administrative, technical, or material support (i.e., reporting or organizing data, constructing databases): G. Gammelgard, H. Hagberg

Other (Sponsor representative of the clinical trial): A. Loskog

\section{Acknowledgments}

The authors thank the research nurses Margareta Kvitz and Louise Lunt at Uppsala University Hospital and technical assistant Gabriella Paul Wetterberg at Uppsala University for supporting the execution of the trial. The trial was funded by grants to A. Loskog, G. Enblad, and M. Essand from AFA Insurance AB, Sweden, the Swedish Cancer Society, the Swedish Research Council, the Lions fund at Uppsala University Hospital, and the Swedish State Support for Clinical Research (ALF). Infrastructural support was obtained from Swedish Foundation for Strategic Research.

The costs of publication of this article were defrayed in part by the payment of page charges. This article must therefore be hereby marked advertisement in accordance with 18 U.S.C. Section 1734 solely to indicate this fact.

Received February 7, 2018; revised May 1, 2018; accepted August 7, 2018 ; published first August 10, 2018.

chimeric T cell receptor possessing CD28 and CD137 costimulatory domains. Hum Gene Ther 2007;18:712-25.

9. Cheson BD, Horning SJ, Coiffier B, Shipp MA, Fisher RI, Connors JM, et al Report of an international workshop to standardize response criteria for non-Hodgkin's lymphomas. NCI Sponsored International Working Group. J Clin Oncol 1999;17:1244

10. Hallek M, Cheson BD, Catovsky D, Caligaris-Cappio F, Dighiero G, Döhner $\mathrm{H}$, et al. Guidelines for the diagnosis and treatment of chronic lymphocytic leukemia: a report from the International Workshop on Chronic Lymphocytic Leukemia updating the National Cancer Institute-Working Group 1996 guidelines. Blood 2008;111:5446-56.

11. Karlsson H, Svensson E, Gigg C, Jarvius M, Olsson-Strömberg U, Savoldo B, et al. Evaluation of intracellular signaling downstream chimeric antigen receptors. PLoS One 2015;10:e0144787.

12. Carpenito C, Milone MC, Hassan R, Simonet JC, Lakhal M, Suhoski MM et al. Control of large, established tumor xenografts with genetically retargeted human $\mathrm{T}$ cells containing CD28 and CD137 domains. Proc Natl Acad Sci U S A 2009;106:3360-5.

13. Turtle CJ, Hanafi LA, Berger C, Gooley TA, Cherian S, Hudecek M, et al. CD19 CAR-T cells of defined CD4+:CD8 + composition in adult B cell ALL patients. J Clin Invest 2016;126:2123-38.

14. DeFrancesco L. CAR-T's forge ahead, despite Juno deaths. Nat Biotechnol 2017;35:6-7.

15. Turtle CJ, Hay KA, Hanafi LA, Li D, Cherian $S$, Chen $X$, et al Durable molecular remissions in chronic lymphocytic leukemia treated 
with CD19-specific chimeric antigen receptor-modified T cells after failure of ibrutinib. J Clin Oncol 2017;35:3010-20

16. Abbasi J. Amid FDA approval filings, another CAR-T therapy patient death JAMA 2017;317:2271.

17. Till BG, Jensen MC, Wang J, Qian X, Gopal AK, Maloney DG, et al. CD20 specific adoptive immunotherapy for lymphoma using a chimeric antigen receptor with both $\mathrm{CD} 28$ and $4-1 \mathrm{BB}$ domains: pilot clinical trial results. Blood 2012;119:3940-50.

18. Morgan RA, Yang JC, Kitano M, Dudley ME, Laurencot CM, Rosenberg SA Case report of a serious adverse event following the administration of $\mathrm{T}$ cells transduced with a chimeric antigen receptor recognizing ERBB2. Mol Ther 2010;18:843-51.

19. Locke FL, Neelapu SS, Bartlett NL, Siddiqi T, Chavez JC, Hosing CM, et al. Phase 1 results of ZUMA-1: a multicenter study of KTE-C19 antiCD19 CAR T cell therapy in refractory aggressive lymphoma. Mol Ther 2017;25:285-95.

20. Park JH, Riviere I, Gonen M, Wang X, Sénéchal B, Curran KJ, et al. Long-term follow-up of CD19 CAR therapy in acute lymphoblastic leukemia. N Engl J Med 2018;378:449-59.

21. Four M, Cacheux V, Tempier A, Platero D, Fabbro M, Marin G, et al. PD1 and PDL1 expression in primary central nervous system diffuse large B-cell lymphoma are frequent and expression of PD1 predicts poor survival. Hematol Oncol 2017;35:487-96.

22. Nacinovic-Duletic A, Stifter S, Dvornik S, Skunca Z, Jonjic N. Correlation of serum IL-6, IL-8 and IL-10 levels with clinicopathological features and prognosis in patients with diffuse large B-cell lymphoma. Int J Lab Hematol 2008;30:230-9
23. Klupp F, Neumann L, Kahlert C, Diers J, Halama N, Franz C, et al. Serum MMP7, MMP10 and MMP12 level as negative prognostic markers in colon cancer patients. BMC Cancer 2016;16:494.

24. Parker KH, Beury DW, Ostrand-Rosenberg S. Myeloid-derived suppressor cells: critical cells driving immune suppression in the tumor microenvironment. Adv Cancer Res 2015;128:95-139.

25. Giachelia M, Voso MT, Tisi MC, Martini M, Bozzoli V, Massini G, et al. Interleukin- 6 plasma levels are modulated by a polymorphism in the NFkappaB1 gene and are associated with outcome following rituximabcombined chemotherapy in diffuse large B-cell non-Hodgkin lymphoma. Leuk Lymphoma 2012;53:411-6.

26. Chong EA, Melenhorst JJ, Lacey SF, Ambrose DE, Gonzalez V, Levine BL, et al. PD-1 blockade modulates chimeric antigen receptor (CAR)-modified T cells: refueling the CAR. Blood 2017;129:1039-41.

27. Wu C, Wu X, Liu X, Yang P, Xu J, Chai Y, et al. Prognostic significance of monocytes and monocytic myeloid-derived suppressor cells in diffuse large B-cell lymphoma treated with R-CHOP. Cell Physiol Biochem 2016 39:521-30.

28. Azzaoui I, Uhel F, Rossille D, Pangault C, Dulong J, Le Priol J, et al. T-cell defect in diffuse large B-cell lymphomas involves expansion of myeloidderived suppressor cells. Blood 2016;128:1081-92.

29. Eriksson E, Wenthe J, Irenaeus S, Loskog A, Ullenhag G. Gemcitabine reduces MDSCs, tregs and TGFbeta- 1 while restoring the teff/treg ratio in patients with pancreatic cancer. J Transl Med 2016;14:282.

30. Maude SL, Frey N, Shaw PA, Aplenc R, Barrett DM, Bunin NJ, et al. Chimeric antigen receptor T cells for sustained remissions in leukemia. N Engl J Med 2014;371:1507-17. 